\title{
Neuronal nitric oxide synthase, nNOS, regulates renal hemodynamics in the postnatal developing piglet
}

\author{
Justin Rodebaugh', Miroslav Sekulic' ${ }^{1}$ William Davies', Stephanie Montgomery', Ali Khraibi', Michael J. Solhaug' \\ and Brian B. Ratliff
}

INTRODUCTION: Nitric oxide (NO) vasodilation critically modulates renal hemodynamics in the neonate compared with the adult. Based on the postnatal expression pattern of renal neuronal nitric oxide synthase (nNOS), the hypothesis was that nNOS is the major NOS isoform regulating renal hemodynamics in the immature, but not mature, kidney.

RESULTS: NOS inhibitors did not alter mean arterial pressure (MAP) in either group. Intrarenal S-methyl-L-thiocitrulline (L-SMTC) in newborns significantly reduced renal blood flow (RBF) $38 \pm 4 \%$, glomerular filtration rate (GFR) $42 \pm 6 \%$, and increased renal vascular resistance (RVR) $37 \pm 7 \%$, whereas intrarenal L-nitro-arginine methyl ester (L-NAME) affected RBF, GFR, and RVR equivalent to L-SMTC treatment. When L-NAME was administered after L-SMTC treatment, newborn renal hemodynamic changes were not further altered from what was observed when L-SMTC was administered alone. In contrast, in the adult, only intrarenal L-NAME, and not L-SMTC, affected renal hemodynamic responses.

DISCUSSION: In conclusion, these studies demonstrate that nNOS is an important regulator of renal hemodynamics in the newborn kidney, but not in the adult.

METHODS: Experiments compared renal hemodynamic responses with intrarenal infusion of L-NAME, an inhibitor of all NOS isoforms, with the selective nNOS inhibitor L-SMTC in the newborn piglet and the adult pig.

$\mathbf{R}^{\mathrm{e}}$ enal function after birth in mammals is characterized by higher renal vascular resistance (RVR), lower renal blood flow (RBF), and a lower glomerular filtration rate (GFR) than in the adult counterpart (1). Various studies have shown that nitric oxide $(\mathrm{NO})$ plays a much more pronounced role in the neonate's hemodynamic state, as compared with the adult's, and NO counterbalances the highly activated reninangiotensin system (RAS), protecting the immature kidney from the deleterious effects of adverse perinatal events that lead to vasomotor acute renal failure (2-7). The immature renal vasculature is highly responsive to intrarenal NO stimulation with acetylcholine and NO inhibition with the nonselective nitric oxide synthase (NOS) inhibitor L-nitro-arginine methyl ester (L-NAME) (8-11), producing significantly greater increases in
RVR and decreases in RBF and GFR in the immature kidney, as compared with the adult. However, because all previous studies in the developing kidney have utilized the nonselective NOS inhibitor L-NAME, it is not known which NOS isoform-endothelial NOS (eNOS) or neuronal NOS (nNOS) predominately regulates immature renal hemodynamics.

All three NOS isoforms-nNOS, eNOS, and inducible NOS (iNOS) - are present in the adult kidney (12-15). However, iNOS is present in low basal abundance in both adult and immature kidney (3) and does not play a role in normal physiologic renal hemodynamic function (15). Despite recent reports suggesting a renal hemodynamic role for nNOS in the adult rat during pathological stress $(16,17)$, such as hypertension and diabetes, nNOS does not appear to play a role in healthy adult basal renal hemodynamics. For example, Kakoki et al., using two nNOS-specific inhibitors, $N$-propyl-L-arginine (L-NPA) and vinyl-L-N-5-L-ornithine (L-VNIO),reported that nNOS does not regulate basal renal blood flow in healthy adult rats (18). However, several characteristics of nNOS in postnatal renal maturation suggest that this isoform may participate significantly in renal hemodynamics in the neonate after birth. In previous studies by our laboratory, we observed both developmentally upregulated NOS enzymatic activity and nNOS mRNA and protein expression in the kidney during the postnatal period $(19,20)$. In fact, NOS enzymatic activity in the preglomerular-resistance vasculature of the newborn is fourfold greater than that of the adult (19). During the newborn period of enhanced NO production, basal eNOS expression in renal resistance vessels and throughout the immature kidney is significantly downregulated. However, unlike in the adult, nNOS expression and protein are upregulated within the newborn's renal vasculature, including a sevenfold increase in the afferent arteriole where NO production is significantly enhanced (20). nNOS also exhibits a distinct postnatal maturational expression pattern in the macula densa of the maturing rat, a site that further influences renal hemodynamics $(14,21,22)$. In addition, nNOS demonstrates an interdependent morphologic relationship and possible critical renal hemodynamic regulatory interaction with the RAS $(2,19,21,23)$, with crucial NO production counterbalancing 
the enhanced vasoresistance offered by the upregulated RAS during renal development (2-7).

Currently, there are no studies investigating the role of nNOS in the renal hemodynamics of the newborn. Given the postnatal developmental characteristics of nNOS expression and NOS activity in whole kidney and glomerular resistance vessels of the neonate, in addition to the interplay between NOS and the RAS, we generated the hypothesis that nNOS is the major isoform regulating renal hemodynamics in the immature kidney, but not in the mature adult kidney. The objective of these studies was to compare the renal hemodynamic responses with the intrarenal infusion of the selective nNOS inhibitor S-methyl-L-thiocitrulline (L-SMTC) with the intrarenal infusion of the nonselective NOS inhibitor L-NAME in both the newborn and adult pig.

\section{RESULTS}

To exclude systemic effects, we conducted initial experiments, which confirmed that the doses of L-NAME and L-SMTC used in intrarenal infusions did not alter MAP from control values in all age groups studied, as shown in Table 1. Basal MAP in newborn piglets was significantly lower than adult pig basal MAP. In time-control experiments, animals received intrarenal vehicle $(0.9 \%$ saline) in place of L-SMTC or L-NAME during the 75-min experimental infusion period. Vehicle intrarenal infusion alone demonstrated no significant change in GFR, RBF, or RVR in either age group (Table 2).

As shown previously $(6,9,11)$, we also observed basal RVR significantly higher in the newborn porcine kidney as compared with the adult kidney. Following inhibition of all NOS isoforms in the newborn kidney with L-NAME intrarenal infusion, RVR significantly increased from the control level of $2.78 \pm$ $0.18 \mathrm{~mm} \mathrm{Hg} / \mathrm{ml} / \mathrm{min}$ to $3.79 \pm 0.11 \mathrm{~mm} \mathrm{Hg} / \mathrm{ml} / \mathrm{min}$ (Figure 1). When L-SMTC was intrarenally infused, RVR increased from $2.72 \pm 0.3 \mathrm{~mm} \mathrm{Hg} / \mathrm{ml} / \mathrm{min}$ to $3.75 \pm 0.31 \mathrm{~mm} \mathrm{Hg} / \mathrm{ml} / \mathrm{min}$ (Figure 1). L-NAME and L-SMTC treatment resulted in nearly identical enhancement of RVR. When L-NAME and L-SMTC were intrarenally infused together or sequentially, no additive effect was observed; RVR did not increase further than what was observed for either L-NAME or L-SMTC infusion alone (Table 2). Intrarenal infusion of L-NAME also increased RVR in the adult kidney; however, nNOS blockade with L-SMTC had no effect on adult RVR (Figure 1).

A similar pattern was seen in RBF responses to NOS inhibition with L-NAME or L-SMTC. Consistent with our previous findings, basal RBF is significantly lower in the newborn than in the adult $(6,11)$. Intrarenal L-NAME significantly decreased

Table 1. Effect of intrarenal perfusion of L-NAME and L-SMTC on MAP in newborn piglets and adult pigs

\begin{tabular}{lcccr}
\hline & \multicolumn{4}{c}{ MAP $(\mathrm{mm} \mathrm{Hg})$} \\
\cline { 2 - 5 } & Control & L-NAME & Control & \multicolumn{1}{c}{ L-SMTC } \\
\hline Newborn & $97.2 \pm 2$ & $96.9 \pm 3$ & $95.9 \pm 5$ & $96.3 \pm 5$ \\
Adult & $112.4 \pm 4$ & $115.3 \pm 3$ & $119.6 \pm 2$ & $120.9 \pm 2$ \\
\hline $\begin{array}{l}\text { L-NAME, L-nitro-arginine methyl ester; L-SMTC, S-methyl-L-thiocitrulline; MAP, mean } \\
\text { arterial pressure. }\end{array}$
\end{tabular}

RBF in the newborn kidney from $1.24 \pm 0.18 \mathrm{ml} / \mathrm{min} /$ grams of kidney weight (gkw) to $0.8 \pm 0.11 \mathrm{ml} / \mathrm{min} / \mathrm{gkw}$ (Figure 2). Again, nNOS-specific inhibition with L-SMTC resulted in RBF attenuation comparable with that observed with L-NAME infusion. L-SMTC treatment caused RBF in the newborn to significantly decrease from $1.22 \pm 0.2 \mathrm{ml} / \mathrm{min} / \mathrm{gkw}$ to $0.74 \pm$ $0.13 \mathrm{ml} / \mathrm{min} / \mathrm{gkw}$ (Figure 2). When L-NAME and L-SMTC were intrarenally infused together or sequentially, no additive effect was observed; RBF did not decrease further than what was observed for either L-NAME or L-SMTC infusion alone (Table 2). In the adult, only L-NAME infusion resulted in a reduction in RBF. RBF remained unaffected by treatment with L-SMTC (Figure 2).

Figure 3 demonstrates GFR responses to intrarenal infusion of the NOS inhibitors. Basal GFR in the newborn was

Table 2. Effect of intrarenal perfusion of $L-S M T C$ in combination or with subsequent L-NAME infusion on RVR, RBF, and GFR in newborn piglets and adult pigs

\begin{tabular}{|c|c|c|c|c|}
\hline & $\begin{array}{l}\text { Intrarenal } \\
\text { infusion }\end{array}$ & $\begin{array}{c}\mathrm{RVR}(\mathrm{mm} \\
\mathrm{Hg} / \mathrm{ml} / \mathrm{min})\end{array}$ & $\begin{array}{l}\mathrm{RBF}(\mathrm{ml} / \\
\mathrm{min} / \mathrm{gkw})\end{array}$ & $\begin{array}{c}\mathrm{GFR}(\mathrm{ml} / \\
\mathrm{min} / \mathrm{gkw})\end{array}$ \\
\hline \multirow[t]{5}{*}{ Newborn } & Control & $2.71 \pm 0.33$ & $1.22 \pm 0.22$ & $0.37 \pm 0.05$ \\
\hline & L-SMTC & $3.75 \pm 0.31$ & $0.74 \pm 0.13$ & $0.21 \pm 0.06$ \\
\hline & $\begin{array}{l}\text { L-SMTC + } \\
\text { L-NAME }\end{array}$ & $3.72 \pm 0.28$ & $0.76 \pm 0.22$ & $0.23 \pm 0.04$ \\
\hline & $\begin{array}{l}\text { L-SMTC followed } \\
\text { by L-NAME }\end{array}$ & $3.74 \pm 0.38$ & $0.75 \pm 0.19$ & $0.22 \pm 0.05$ \\
\hline & $\begin{array}{l}\text { Vehicle } \\
\text { (0.9\% saline) }\end{array}$ & $2.74 \pm 0.42$ & $1.24 \pm 0.26$ & $0.38 \pm 0.08$ \\
\hline \multirow[t]{5}{*}{ Adult } & Control & $1.25 \pm 0.15$ & $1.95 \pm 0.25$ & $0.73 \pm 0.06$ \\
\hline & L-SMTC & $1.25 \pm 0.25$ & $1.89 \pm 0.23$ & $0.76 \pm 0.05$ \\
\hline & $\begin{array}{l}\text { L-SMTC + } \\
\text { L-NAME }\end{array}$ & $1.78 \pm 0.22$ & $1.39 \pm 0.13$ & $0.67 \pm 0.04$ \\
\hline & $\begin{array}{l}\text { L-SMTC followed } \\
\text { by L-NAME }\end{array}$ & $1.71 \pm 0.16$ & $1.44 \pm 0.31$ & $0.69 \pm 0.03$ \\
\hline & $\begin{array}{l}\text { Vehicle } \\
\text { (0.9\% saline) }\end{array}$ & $1.27 \pm 0.23$ & $1.93 \pm 0.27$ & $0.72 \pm 0.06$ \\
\hline
\end{tabular}

GFR, glomerular filtration rate; $\mathrm{gkw}$, gram of kidney weight; L-NAME, L-nitro-arginine methyl ester; L-SMTC, S-methyl-L-thiocitrulline; RBF, renal blood flow; RVR, renal vascular resistance.

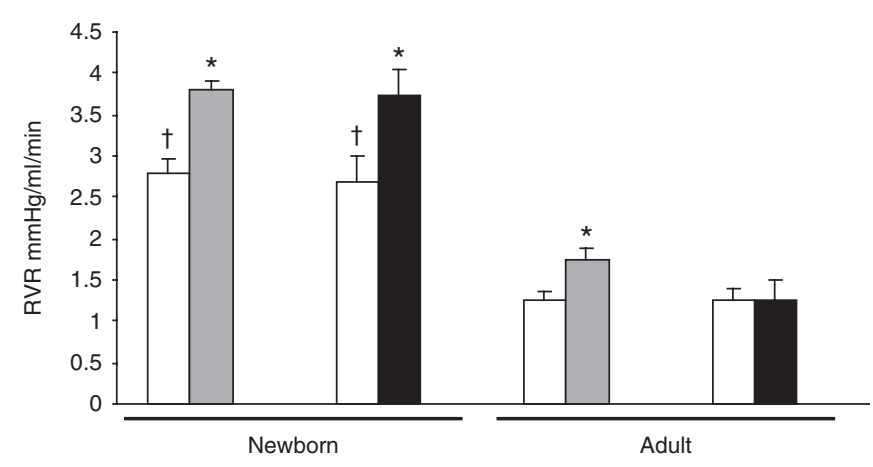

Figure 1. The effects of intrarenal arterial infusion of L-NAME $(\square)$ and L-SMTC ( $\square$ ) on RVR in newborn piglets and adults. ${ }^{*} P<0.05$ vs. control ( $\square$ ); ${ }^{\dagger} P<0.05$ vs. adult. L-NAME, L-nitro-arginine methyl ester; L-SMTC, S-methylL-thiocitrulline; RVR, renal vascular resistance. 
significantly lower compared with that in the adult, as seen in our previous reports $(6,11)$. L-NAME infusion in the newborn reduced GFR from $0.37 \pm 0.03 \mathrm{ml} / \mathrm{min} / \mathrm{gkw}$ to $0.21 \pm 0.05 \mathrm{ml} / \mathrm{min} / \mathrm{gkw}$ (Figure 3). Intrarenal L-SMTC produced a similar decrease in GFR in the newborn piglet, from

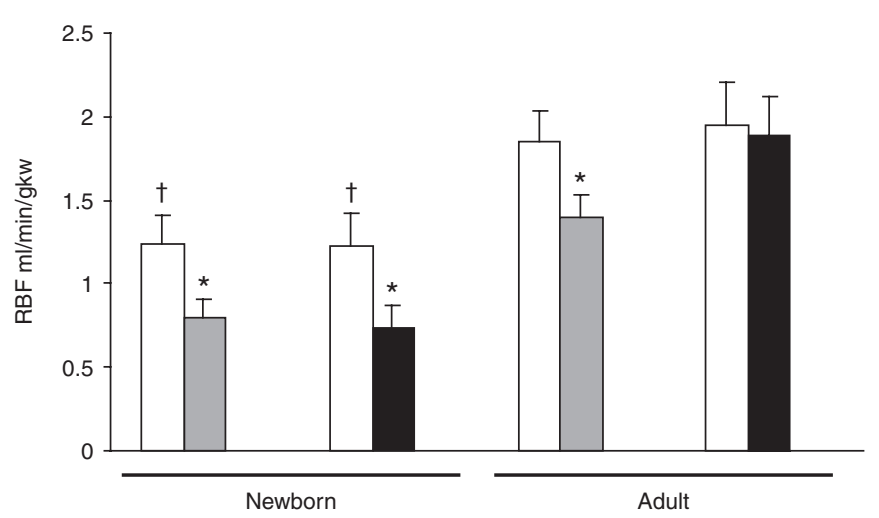

Figure 2. The effects of intrarenal arterial infusion of L-NAME $(\square)$ and L-SMTC ( $\square)$ on RBF in newborn piglets and adults. ${ }^{*} P<0.05$ vs. control ( $\square$ ); ${ }^{+} P<0.05$ vs. adult. L-NAME, L-nitro-arginine methyl ester; L-SMTC, S-methylL-thiocitrulline; RBF, renal blood flow.

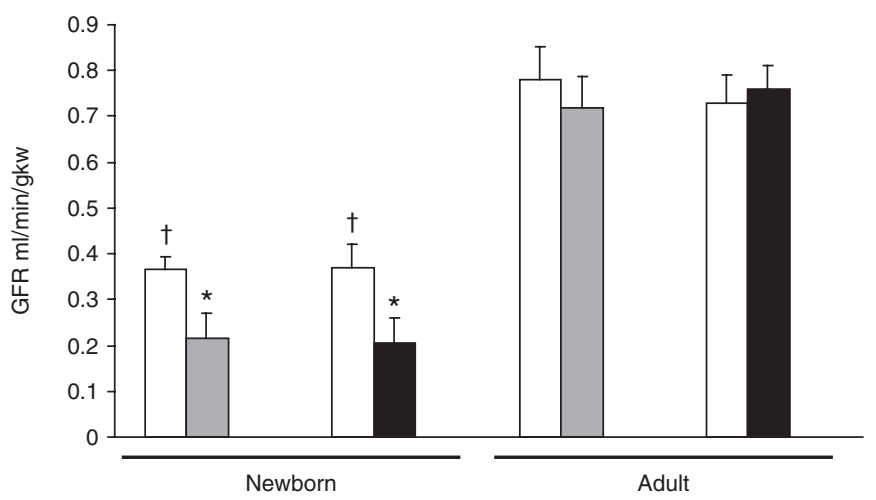

Figure 3. The effects of intrarenal arterial infusion of L-NAME ( $\square)$ and L-SMTC ( $\square)$ on GFR in newborn piglets and adults. ${ }^{*} P<0.05$ vs. control $(\square)$; ${ }^{+} P<0.05$ vs. adult. GFR, glomerular filtration rate; L-NAME, L-nitro-arginine methyl ester; L-SMTC, S-methyl-L-thiocitrulline.
$0.37 \pm 0.05 \mathrm{ml} / \mathrm{min} / \mathrm{gkw}$ to $0.20 \pm 0.06 \mathrm{ml} / \mathrm{min} / \mathrm{gkw}$ (Figure 3 ). When L-NAME and L-SMTC were intrarenally infused together or sequentially, no additive effect was observed; GFR did not decrease further than what was observed for either L-NAME or L-SMTC infusion alone (Table 2). Supporting our previous findings, intrarenal L-NAME in the adult did not significantly alter GFR $(10,11)$ (Figure 3). GFR was not significantly changed in the adult pig after the intrarenal infusion of L-SMTC.

The percent changes in RVR, RBF, and GFR were all statistically the same when either L-NAME or L-SMTC was intrarenally administered to the newborn (Figure 4). RVR increased $37 \%$, RBF decreased between 35 and 38\%, and GFR decreased between 41 and $43 \%$ when either all NOS isoforms were inhibited with L-NAME or when only nNOS was blocked with L-SMTC (Figure 4). This suggests nNOS as the major source of NO production within the immature kidney and not eNOS. To validate this theory, in one series of experiments, we simultaneously infused L-NAME and L-SMTC and in a second series of experiments, we intrarenally infused L-SMTC to block nNOS followed by sequential blockade of all NOS isoforms with infusion of L-NAME. In both experiments, additional treatment with L-NAME did not exacerbate any L-SMTC-induced changes in newborn RVR, RBF, or GFR, thus indicating that the observed changes are indeed dependent on the L-SMTC inhibited source of NOS, nNOS (Table 2). In the adult, nNOSspecific inhibition did not affect RVR, RBF, or GFR, and L-NAME inhibition did alter renal hemodynamics, thereby indicating that eNOS, not nNOS, is the major contributor of $\mathrm{NO}$ in adult renal hemodynamics.

Further highlighting the renal effects of nNOS inhibition in the newborn are the effects of L-NAME and L-SMTC intrarenal infusion on urine volume (Figure 5). L-NAME and L-SMTC comparably decreased urine volume in the newborn. In the adult, basal urine volume was substantially elevated. Only L-NAME treatment was capable of attenuating urine volume; L-SMTC treatment was without significant effect in the adult (Figure 5).

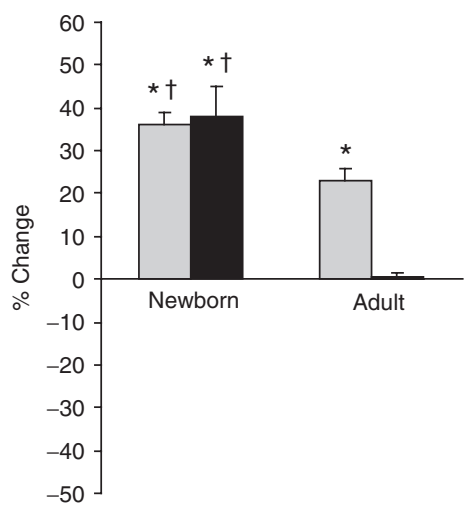

RVR

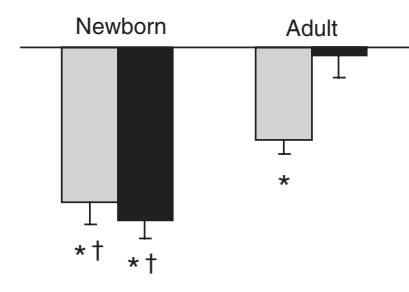

RBF

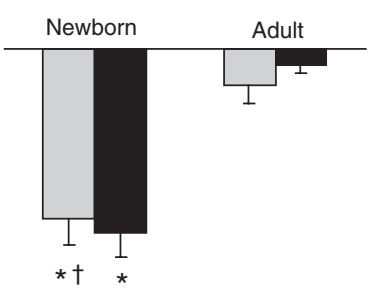

GFR

Figure 4. The percent changes of RVR, RBF, and GFR caused by the intrarenal arterial infusion of L-NAME ( $\square$ ) and L-SMTC ( $\square$ ) in newborn piglets and adults. ${ }^{*} P<0.05$ vs. control $(\square){ }^{\dagger} P<0.05$ vs. adult. GFR, glomerular filtration rate; L-NAME, L-nitro-arginine methyl ester; L-SMTC, S-methyl-L-thiocitrulline; $\mathrm{RBF}$, renal blood flow; RVR, renal vascular resistance. 


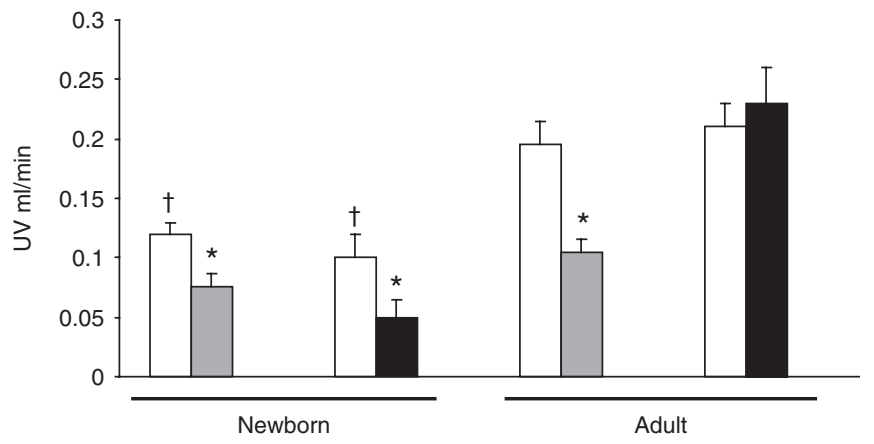

Figure 5. The effects of intrarenal arterial infusion of L-NAME ( $\square$ ) and L-SMTC ( $\square)$ on UV in newborn piglets and adults. ${ }^{*} P<0.05$ vs. control $(\square)$; ${ }^{\dagger} P<0.05$ vs. adult. L-NAME, L-nitro-arginine methyl ester; L-SMTC, S-methylL-thiocitrulline; UV, urine volume.

\section{DISCUSSION}

The newborn's renal hemodynamic state is characterized by high RVR, which results in low RBF (24-26). The major factor that causes the newborn's elevated RVR is enhancement of the RAS $(2,9,11,27,28)$. Although reports have indicated that adaptations in the sensitivity of vascular smooth muscle to NO increase after birth, studies have demonstrated an enhanced role of $\mathrm{NO}$ in the newborn's renal hemodynamic state $(2,9,11,27-29)$. Various reports have shown that NO vasodilation is crucial in counterbalancing the highly activated RAS and its accompanying vasoconstriction that predisposes the newborn kidney to develop vasomotor acute renal failure (2-7). Solhaug et al. were the first to show an enhanced role for NO in the neonate in 1993, when intrarenal infusion of the nonspecific NOS inhibitor L-NAME into porcine caused significantly greater changes in RVR, RBF, and GFR in the newborn, than in the adult (6). This finding by Solhaug et al. was confirmed in other animal models (lambs and rabbits) in which nonspecific NOS inhibition increased RVR while decreasing RBF and GFR much more significantly in neonates than in adult kidneys $(4,5,8)$. These early studies demonstrated that the renal hemodynamics of the neonate is much more dependent on NO than that of the adult to maintain normal physiological function; however, the characteristics and exact nature of the enhanced role of NO remain unidentified.

Until recently, research on NOS and NO production in the kidney has been exclusive to the adult. Various laboratories have identified eNOS throughout the adult kidney including abundant expression in the renal vasculature, and functional studies have demonstrated eNOS as the major isoform that provides NO vasorelaxation within the adult kidney (12,13,30-32). Although various groups have identified nNOS within the adult's pre- and postglomerular resistance vessels and tubules, the greatest localization of nNOS occurs in the macula densa of the adult kidney, where it plays a critical role in the tubuloglomerular feedback mechanism $(12,13,31,32)$. In contrast to the adult kidney, initial studies on the developing kidney have indicated nNOS expression to be more widespread in the neonate kidney, with nNOS expression that appears to follow the developmentally regulated expression of the RAS (21,33-35).
Whereas the effect nNOS has in regulating renin secretion in the newborn is unexamined, NOS inhibition in the adult has been found to both inhibit and enhance renin release (36). NO is known to inhibit cyclic adenosine monophosphate degradation through cyclic GMP-mediated mechanisms, thereby stimulating renin secretion, whereas cellular calcium influx and protein kinase $\mathrm{K}$ activation inhibit renin release (36). Studies by Solhaug et al. and Ratliff et al. demonstrated that nNOS and the RAS have very similar developmental patterns and that angiotensin II (ANG II) upregulates nNOS mRNA and protein expression and NOS activity via the ANG II type 1 and ANG II type 2 receptors in the neonate $(3,11,19)$. In studies by Ratliff et al., it was demonstrated that NO production in the preglomerular resistance vasculature is threefold higher in the newborn than in the adult $(19,20)$. During the newborn's period of increased NO production, eNOS expression is minimally detectable, with protein levels sevenfold less than what is observed in the adult (20). However, nNOS expression in whole-kidney models and in microdissected preglomerular resistance vessels is significantly enhanced in the newborn and strongly suggests that the nNOS isoform, and not eNOS, is the major NOS isoform contributing NO to the newborn's renal hemodynamic state $(3,19,20)$.

Despite expressional and protein studies on NOS expression in the newborn kidney that demonstrated significantly enhanced nNOS expression, the appropriate functional studies are missing that would allow investigation and determination of the role of nNOS in newborn renal hemodynamics. To address this dilemma, we aimed to investigate the physiological effects of nNOS inhibition on the renal hemodynamic state of the newborn. First, we observed an enhanced effect of NO in the newborn's renal hemodynamics when total NOS was inhibited by the unspecific NOS isoform inhibitor L-NAME, a finding that supports previous reports $(6,9,11,37)$. When the nNOS-specific inhibitor L-SMTC was intrarenally perfused, RVR, RBF, and GFR were affected to the same extent as when L-NAME was perfused alone (Figures 1-4). This suggested that the vasodilatory effects of NO were produced by the nNOS isoform. However, the kinetics of the blockade of nNOS with L-SMTC and any compensatory mechanisms that may involve eNOS still required evaluation. To address this concern, we also intrarenally perfused L-NAME after nNOS inhibition with L-SMTC to determine if other NOS isoforms (primarily eNOS) affect newborn RVR, $\mathrm{RBF}$, and GFR. After nNOS inhibition, the measured renal hemodynamic parameters were not affected by additional eNOS blockade with L-NAME, indicating that only nNOS plays a role in the renal hemodynamics of the newborn (Table 2). In fact, L-NAME (alone or in combination with L-SMTC) intrarenal perfusion resulted in identical modification of renal hemodynamics as when L-SMTC was used alone, in combination with, or in sequence with L-NAME (Table 2). The absence of any additive effect when L-NAME was intrarenally perfused in addition or in sequence with L-SMTC illustrates the lack of significantly relevant NO production by renal eNOS in the newborn kidney. Interestingly, 
upon L-NAME administration, GFR was decreased only in the newborn, suggesting the newborn kidney is unable to maintain a constant GFR, possibly due to (i) immaturity of the renal autoregulatory response system and/or compensatory mechanisms, (ii) prevention of any regulatory response that involves increased ANG II (particularly in the efferent arteriole) because of the enhanced RVR and RAS of the newborn, and/or (iii) the influence of developmental changes in ANG II receptor expression.

In conclusion, the findings here demonstrate nNOS as the critical NOS isoform that takes part in the newborn's renal hemodynamic state. Whereas previous work by Solhaug et al. and Ratliff et al. have identified a critical role for NO in the immature kidney and suggest it may be a result of upregulated nNOS, the findings here provide the functional evidence that supports the enhanced role of nNOS, not eNOS, in the newborn's renal hemodynamic state. The role of nNOS in the newborn is similar to findings during pregnancy, in which it has been reported that upregulated nNOS is responsible for increased NO production, resulting in increased RBF and GFR despite reduced MAP $(38,39)$. These similarities suggest that maternal renal hemodynamic characteristics are carried over into the newborn and/or that intrinsic compensatory mechanisms involving nNOS are similar between mother and newborn during physiological transition periods.

\section{METHODS}

\section{Subjects}

All experiments involving animal usage fulfilled the American Veterinary Medical Association (AVMA) guidelines and were conducted and approved by the Institutional Animal Care and Use Committee (IACUC) at Eastern Virginia Medical School. The animal study protocol is in accordance with the National Institutes of Health Guide for the Care and Use of Laboratory Animals.

Experiments were performed on mixed-breed piglets. Piglets were less than 7 days old, and adult pigs with mature renal function had an average age of 71.5 days. All groups received the same experimental preparation. As in our previous studies with developing piglets $(6,11)$, all animals were fed a standard age-specific swine diet with normal sodium content (Southern States Cooperative, Richmond, VA).

\section{NOS inhibitors and age groups}

Experiments here utilized the selective nNOS inhibitor, L-SMTC, which allows for easy infusion into the renal artery due to its excellent water-soluble properties $(40,41)$. L-SMTC has been used in several studies to examine the role of nNOS in renal hemodynamics including the blood-perfused juxtamedullary nephron preparation (40) and intrarenal infusion $(16,42,43)$. The dose of $0.027 \mu \mathrm{g} / \mathrm{kg} / \mathrm{min}$ for $75 \mathrm{~min}$ in these experiments is based on studies that used L-SMTC intrarenal infusion $(42,44)$. The nonselective NOS inhibitor (L-NAME) at the dose of $3.0 \mu \mathrm{g} / \mathrm{kg} / \mathrm{min}$ for $75 \mathrm{~min}$ was chosen based on our previous studies $(6,11)$. L-SMTC was infused in newborn piglets $(n=8)$ and adult pigs $(n=8)$. L-NAME was infused in newborn piglets $(n=8)$ and adult pigs $(n=8)$.

\section{Preparation}

Animals were fed a standard age-specific pig diet and were fasted overnight before experiments with access to water. Animals received initial anesthesia with intramuscular ketamine (adults $10 \mathrm{mg} / \mathrm{kg}$; piglets $5 \mathrm{mg} / \mathrm{kg}$ ) followed by intravenous sodium pentobarbital bolus $(10 \mathrm{mg} / \mathrm{kg})$ and sustaining anesthesia with intermittent intravenous sodium pentobarbital boluses $(0.5 \mathrm{mg} / \mathrm{kg}$ each). After tracheostomy, animals were ventilated with a respirator (Harvard Apparatus, South
Natick, MA), and constant low flow oxygen was given at $250-500 \mathrm{ml} /$ $\mathrm{min}$. Cannulas were placed in both external jugular veins for infusion of radioisotope and electrolyte solution. The left carotid artery was cannulated for monitoring mean arterial pressure (MAP) and blood sampling. The left kidney was exposed through a retroperitoneal flank incision, and the left ureter was cannulated for timed urine collections. Electromagnetic flow probes (Carolina Instruments Electronics, King, NC) were placed around the renal artery and renal vein to monitor renal blood flow. A 25-gauge right-angle needle was placed in the proximal renal artery for intrarenal infusions.

\section{Experimental protocol}

The experimental design employed in these studies follows the protocol previously described $(6,11)$. In brief, after surgery, animals undergo a 60 -min recovery control period with subsequent sampling, followed by a 75-min experimental period of L-NAME or L-SMTC infusion and another subsequent sampling. Each animal serves as its own control for experimental infusions. Animals receiving vehicle instead of L-NAME/L-SMTC were also used as additional controls. MAP and RBF were monitored continuously throughout the experiment and recorded. All animals received a continuous intravenous maintenance infusion of $5 \%$ dextrose and $0.45 \%$ sodium chloride (electrolyte solution) beginning at $0.03 \mathrm{ml} /$ $\mathrm{kg} / \mathrm{min}$. GFR was determined by the clearance of radioisotope 125 I-iothalamate (Glofil Isotex, Friends Wood, TX). A priming dose of $0.4 \mathrm{mBq} / \mathrm{kg}$ was followed by constant infusion throughout the experiment of $12 \mathrm{mBq}$ at $0.3 \mathrm{ml} / \mathrm{kg} / \mathrm{h}$ for adults and $2.4 \mathrm{mBq}$ at $0.3 \mathrm{ml} / \mathrm{kg} / \mathrm{h}$ for piglets. Intrarenal infusion of $0.9 \%$ saline solution at $0.1 \mathrm{ml} / \mathrm{min}$ was maintained throughout the experimental protocol. After the 60-min recovery control period, a 20-min control urine collection was carried out and a midpoint plasma sample was obtained.

At the end of the control collection period, intrarenal infusion of L-NAME, L-SMTC, or vehicle (0.9\% saline) was started $(0.1 \mathrm{ml} / \mathrm{min})$. Both NOS antagonists were delivered in $0.9 \%$ saline-L-NAME at a rate of $3.0 \mu \mathrm{g} / \mathrm{kg} / \mathrm{min}$, and L-SMTC at a rate of $0.027 \mu \mathrm{g} / \mathrm{kg} / \mathrm{min}$ for 75 min. In all groups, intrarenal infusion of L-NAME, L-SMTC, and vehicle was continued through the final 20-min experimental urine collection and plasma sampling. For L-SMTC infusion followed by L-NAME infusion, L-SMTC was intrarenally infused for the standard 75 min (followed by the 20-min collection period), then L-NAME was infused for an additional $30 \mathrm{~min}$, followed by another 20 -min collection period in which L-NAME was continuously infused. Blood and urine samples were evaluated for 125 I-iothalamate. Animals were euthanized with Euthasol (Delmorva Laboratories, Midlothian, VA).

\section{Statistics}

Results obtained are expressed as means \pm SEM. For multiple comparisons between various age and effects of treatment, a two-way ANOVA with Bonferroni's post-test was performed using GraphPad Prism version 4.00 for Windows (GraphPad, San Diego, CA). Differences were considered significant at $P<0.05$.

\section{STATEMENT OF FINANCIAL SUPPORT}

This work was supported by NIH grant 2R01HL52765-04A2 awarded to M.J.S.

\section{REFERENCES}

1. Seikaly MG, Arant BS Jr. Development of renal hemodynamics: glomerular filtration and renal blood flow. Clin Perinatol 1992;19:1-13.

2. Osborn JL, Hook JB, Bailie MD. Regulation of plasma renin in developing piglets. Dev Pharmacol Ther 1980;1:217-28.

3. Solhaug MJ, Dong XQ, Adelman RD, Dong KW. Ontogeny of neuronal nitric oxide synthase, NOS I, in the developing porcine kidney. Am J Physiol Regul Integr Comp Physiol 2000;278:R1453-9.

4. Ballèvre L, Thonney M, Guignard JP. Nitric oxide modulates glomerular filtration and renal blood flow of the newborn rabbit. Biol Neonate 1996;69:389-98.

5. Sener A, Smith FG. Glomerular and tubular responses to $\mathrm{N}(\mathrm{G})$-nitro-Larginine methyl ester are age dependent in conscious lambs. Am J Physiol Regul Integr Comp Physiol 2002;282:R1512-20. 
6. Solhaug MJ, Wallace MR, Granger JP. Endothelium-derived nitric oxide modulates renal hemodynamics in the developing piglet. Pediatr Res 1993;34:750-4.

7. Török J, Gerová M. Vascular responses after long-term inhibition of nitric oxide synthesis in newborn dogs. Physiol Res 1996;45:323-8.

8. Sener A, Smith FG. Renal hemodynamic effects of L-NAME during postnatal maturation in conscious lambs. Pediatr Nephrol 2001;16:868-73.

9. Simeoni U, Zhu B, Muller C, et al. Postnatal development of vascular resistance of the rabbit isolated perfused kidney: modulation by nitric oxide and angiotensin II. Pediatr Res 1997;42:550-5.

10. Solhaug MJ, Ballèvre LD, Guignard JP, Granger JP, Adelman RD. Nitric oxide in the developing kidney. Pediatr Nephrol 1996;10:529-39.

11. Solhaug MJ, Wallace MR, Granger JP. Nitric oxide and angiotensin II regulation of renal hemodynamics in the developing piglet. Pediatr Res 1996;39:527-33.

12. Bachmann S, Bosse HM, Mundel P. Topography of nitric oxide synthesis by localizing constitutive NO synthases in mammalian kidney. Am J Physiol 1995;268(5 Pt 2):F885-98.

13. Bachmann S, Mundel P. Nitric oxide in the kidney: synthesis, localization, and function. Am J Kidney Dis 1994;24:112-29.

14. Bachmann S, Oberbäumer I. Structural and molecular dissection of the juxtaglomerular apparatus: new aspects for the role of nitric oxide. Kidney Int Suppl 1998;67:S29-33.

15. Mattson DL, Wu F. Nitric oxide synthase activity and isoforms in rat renal vasculature. Hypertension 2000;35(1 Pt 2):337-41.

16. Ichihara A, Imig JD, Navar LG. Neuronal nitric oxide synthase-dependent afferent arteriolar function in angiotensin II-induced hypertension. Hypertension 1999;33(1 Pt 2):462-6.

17. Komers R, Lindsley JN, Oyama TT, Allison KM, Anderson S. Role of neuronal nitric oxide synthase (NOS1) in the pathogenesis of renal hemodynamic changes in diabetes. Am J Physiol Renal Physiol 2000;279: F573-83.

18. Kakoki M, Zou AP, Mattson DL. The influence of nitric oxide synthase 1 on blood flow and interstitial nitric oxide in the kidney. Am J Physiol Regul Integr Comp Physiol 2001;281:R91-7.

19. Ratliff B, Rodebaugh J, Sekulic M, Dong KW, Solhaug M. Nitric oxide synthase and renin-angiotensin gene expression and NOS function in the postnatal renal resistance vasculature. Pediatr Nephrol 2009;24:355-65.

20. Ratliff BB, Sekulic M, Rodebaugh J, Solhaug MJ. Angiotensin II regulates NOS expression in afferent arterioles of the developing porcine kidney. Pediatr Res 2010;68:29-34.

21. Fischer E, Schnermann J, Briggs JP, Kriz W, Ronco PM, Bachmann S. Ontogeny of NO synthase and renin in juxtaglomerular apparatus of rat kidneys. Am J Physiol 1995;268(6 Pt 2):F1164-76.

22. Wilcox CS, Welch WJ, Murad F, et al. Nitric oxide synthase in macula densa regulates glomerular capillary pressure. Proc Natl Acad Sci USA 1992;89:11993-7.

23. Tufro-McReddie A, Gomez RA. Ontogeny of the renin-angiotensin system. Semin Nephrol 1993;13:519-30.

24. Gruskin AB, Edelmann CM Jr, Yuan S. Maturational changes in renal blood flow in piglets. Pediatr Res 1970;4:7-13.

25. Kleinman LI, Lubbe RJ. Factors affecting the maturation of glomerular filtration rate and renal plasma flow in the new-born dog. J Physiol (Lond) 1972;223:395-409.
26. Jose PA, Logan AG, Slotkoff LM, Lilienfield LS, Calcagno PL, Eisner GM. Intrarenal blood flow distribution in canine puppies. Pediatr Res 1971;5:335-44.

27. Pelayo JC, Eisner GM, Jose PA. The ontogeny of the renin-angiotensin system. Clin Perinatol 1981;8:347-59.

28. Wallace KB, Hook JB, Bailie MD. Postnatal development of the reninangiotensin system in rats. Am J Physiol 1980;238:R432-7.

29. Thompson LP, Weiner CP. Acetylcholine relaxation of renal artery and nitric oxide synthase activity of renal cortex increase with fetal and postnatal age. Pediatr Res 1996;40:192-7.

30. Han KH, Lim JM, Kim WY, Kim H, Madsen KM, Kim J. Expression of endothelial nitric oxide synthase in developing rat kidney. Am J Physiol Renal Physiol 2005;288:F694-702.

31. Terada Y, Tomita K, Nonoguchi H, Marumo F. Polymerase chain reaction localization of constitutive nitric oxide synthase and soluble guanylate cyclase messenger RNAs in microdissected rat nephron segments. J Clin Invest 1992;90:659-65.

32. Kone BC. Localization and regulation of nitric oxide synthase isoforms in the kidney. Semin Nephrol 1999;19:230-41.

33. Gabbai FB, Blantz RC. Role of nitric oxide in renal hemodynamics. Semin Nephrol 1999;19:242-50.

34. Schricker K, Pötzl B, Hamann M, Kurtz A. Coordinate changes of renin and brain-type nitric-oxide-synthase (b-NOS) mRNA levels in rat kidneys. Pflugers Arch 1996;432:394-400.

35. Singh I, Grams M, Wang WH, et al. Coordinate regulation of renal expression of nitric oxide synthase, renin, and angiotensinogen mRNA by dietary salt. Am J Physiol 1996;270(6 Pt 2):F1027-37.

36. Kurtz A, Wagner C. Role of nitric oxide in the control of renin secretion. Am J Physiol 1998;275(6 Pt 2):F849-62.

37. Simeoni U, Helwig JJ. [Nitric oxide (NO) and normal and pathologic renal development]. Pediatr Med Chir 1997;19:313-5.

38. Abram SR, Alexander BT, Bennett WA, Granger JP. Role of neuronal nitric oxide synthase in mediating renal hemodynamic changes during pregnancy. Am J Physiol Regul Integr Comp Physiol 2001;281:R1390-3.

39. Smith CA, Santymire B, Erdely A, Venkat V, Losonczy G, Baylis C. Renal nitric oxide production in rat pregnancy: role of constitutive nitric oxide synthases. Am J Physiol Renal Physiol 2010;299:F830-6.

40. Ichihara A, Inscho EW, Imig JD, Navar LG. Neuronal nitric oxide synthase modulates rat renal microvascular function. Am J Physiol 1998;274(3 Pt 2): F516-24.

41. Zhang J, Xu M, Dence CS, Sherman EL, McCarthy TJ, Welch MJ. Synthesis, in vivo evaluation and PET study of a carbon-11-labeled neuronal nitric oxide synthase (nNOS) inhibitor S-methyl-L-thiocitrulline. J Nucl Med 1997;38:1273-8.

42. Cervenka L, Kramer HJ, Malý J, et al. Role of nNOS in regulation of renal function in hypertensive Ren-2 transgenic rats. Physiol Res 2002;51:571-80.

43. Ichihara A, Navar LG. Neuronal NOS contributes to biphasic autoregulatory response during enhanced TGF activity. Am J Physiol 1999;277 (1 Pt 2):F113-20.

44. Vanecková I, Kramer HJ, Malý J, Bäcker A, Bokemeyer D, Cervenka L. Lack of a role of neuronal nitric oxide synthase in the regulation of the renal function in rats fed a low-sodium diet. Kidney Blood Press Res 2002;25:224-31. 